\title{
ESTIMASI DISTRIBUSI BERAT SAYAP DAN DISTRIBUSI LIFT UNTUK OPTIMASI BENDING MOMENT DENGAN SISTEM FUEL TRANSFER PADA PESAWAT BOEING 737-500
}

\author{
Mufti Arifin*, Endah Yuniarti, Rafika Arum Sari, Ahmad Akmal Said \\ Fakultas Teknologi Kedirgantaraan, \\ Universitas Dirgantara Marsekal Suryadarma \\ Komplek Bandara Halim Perdanakusuma, Jakarta 13610, Indonesia \\ "Corresponding Author: muftiarifin@universitassuryadarma.com
}

\begin{abstract}
Abstrak- Selain sebagai penghasil gaya angkat, sayap berfungsi menahan beban yang terjadi pada struktur pesawat, seperti beban geser, puntir dan lentur (bending). Dari semua beban tersebut beban lentur (bending) merupakan beban terbesar yang diterima oleh sayap. Pengaturan beban bending merupakan salah satu faktor utama dalam mengurangi beban yang dialami oleh sayap. Namun, nilai optimal yang ditunjukkan berlawanan antara di darat dan di udara, untuk memanfaatkan keadaan tersebut digunakan sistem fuel transfer load alleviation. Fuel transfer load alleviation merupakan suatu sistem yang otomatis memindahkan fue/lebih banyak di tangki bagian dalam pada saat di darat dan berada di tangki bagian luar pada saat di udara sehingga efek dari beban bending dapat dikurangi. Beban bending yang dihasilkan merupakan hasil penjumlahan antara distribusi berat dan distribusi lift yang terjadi pada sayap sehingga untuk menghitung bending diperlukan data distribusi berat pada sayap. Penelitian ini bertujuan untuk mengetahui distribusi berat dan distribusi lift yang terjadi pada sayap pesawat Boeing 737-500. Nilai distribusi berat dan distribusi lift menghasilkan optimasi moment pada dua keadaan yaitu, di darat dan di udara dengan tiga variasi fuel transfer yaitu, constant dengan nilai 40134,53 N, linier dengan nilai 48059,53 N, dan maximum dengan nilai $172386,50 \mathrm{~N}$.
\end{abstract}

Kata kunci : sayap, fuel transfer, distribusi berat, distribusi lift, beban bending

Abstract - Aside from being a manufacturer of lift force, a wing is functioning hold the load that occurs in the structure of the aircraft, such as the shear load, twist and bending. Of all the load the load bending is the greatest burden are received by the wings. Setting the load bending is one of the major factors in reducing the burden experienced by the wing. However, the optimal value indicated opposite between on land and in the air, to take advantage of the situation to use fuel system transfers the load alleviation. Fuel transfer load alleviation is a system that automatically move the fuel more in the tank at the time in part on land and are on the outside of the tank at the time in the air so that the effect of the load bending bending loads can be reduced, which generated as the result of addition between the weight distribution and the distribution of lift that occurs on the wings so as to calculate the bending data needed weight distribution and the distribution of lift on the wing. This research aims to know the weight distribution occurs on the wings of the Boeing 737-500. The value of the weight distribution and distribution of lift yield optimization moment on two States namely, on land and in the air with three variations of the fuel transfer that is, constant with a value of $40134.53 \mathrm{~N}$, linear with a value of $48059.53 \mathrm{~N}$, and the maximum value of $172386.50 \mathrm{~N}$.

Keywords: wings, fuel transfer, weight distribution, lift distribution, load bending 


\section{PENDAHULUAN}

Pesawat A380 merupakan salah satu transportasi udara terbesar dan memiliki teknologi yang terbaru dalam pengoperasian sistem pesawat. Salah satu teknologi yang dipakai pada pesawat A380 adalah sistem fuel transfer load alleviation.

Fuel transfer load alleviation adalah sistem terbaru yang memanfaatkan sistem Fuel transfer untuk mengurangi beban yang dialami oleh sayap pesawat, terutama beban lentur (bending) yang dialami sayap. Pengaturan beban bending pada sayap merupakan salah satu faktor utama dalam pengurangan beban pesawat, tetapi nilai optimal yang didapatkan berlawanan antara pada saat di darat dan di udara. Untuk memanfaatkan kondisi ini pada dua kondisi tersebut maka digunakan sistem otomatis fuel transfer.

Fuel transfer secara otomatis dilakukan untuk mengatur fue/ berada lebih banyak di tangki bagian dalam pada saat pesawat di darat dan berada lebih banyak di tangki bagian luar pada saat di udara ${ }^{[1]}$. Beban bending yang dihasilkan merupakan hasil perhitungan antara distribusi berat sayap dan distribusi gaya lift yang terjadi pada sayap pesawat sehingga untuk menghasilkan nilai beban bending diperlukan data distribusi gaya lift yang terjadi di sayap pesawat.

Dengan latar belakang berikut, perhitungan dilakukan pada dua kondisi, yaitu kondisi saat pesawat berada di darat dan kondisi pada saat pesawat di udara. Perhitungan berat sayap pesawat dan perhitungan distribusi gaya lift dilakukan dengan metode analitik, dengan metode tersebut dapat diketahui data berat sayap dan nilai distribusi lift dalam bentuk diagram, yang kemudian akan digunakan untuk menghitung beban bending yang terjadi pada sayap pesawat yang akan diteliti.

\section{METODE PENELITIAN}

\subsection{Spesifikasi Pesawat ${ }^{[11]}$}

$\begin{array}{ll}\text { General } & \\ \text { Span } & : 28,9 \mathrm{~m} \\ \text { Length } & : 31 \mathrm{~m} \\ \text { Height } & : 11,1 \mathrm{~m} \\ \text { Cruise speed } & : 796 \mathrm{~km} / \mathrm{h} \\ \text { MTOW } & : 60.550 \mathrm{~kg}\end{array}$

$$
\begin{array}{ll}
\text { MLW } & : 49.890 \mathrm{~kg} \\
\text { Empty weight } & : 31.950 \mathrm{~kg} \\
\text { Zero Fuel } & : 46.490 \mathrm{~kg}
\end{array}
$$

\subsection{Geometri Sayap}

Tabel 2.1 Geometri Sayap B737-500[11]

\begin{tabular}{|l|l|}
\hline Gross area $\left(\mathrm{m}^{2}\right)$ & 91 \\
\hline Aspek Ratio & 9,17 \\
\hline Taper Ratio & 0,240 \\
\hline Root Chord $(\mathrm{m})$ & 7,32 \\
\hline Tip Chord $(\mathrm{m})$ & 1,62 \\
\hline M.A.C $(\mathrm{m})$ & 3,41 \\
\hline Dihedral $\left({ }^{\circ}\right)$ & 6 \\
\hline $1 / 4$ Chord Sweepback $\left(^{\circ}\right)$ & 25 \\
\hline
\end{tabular}

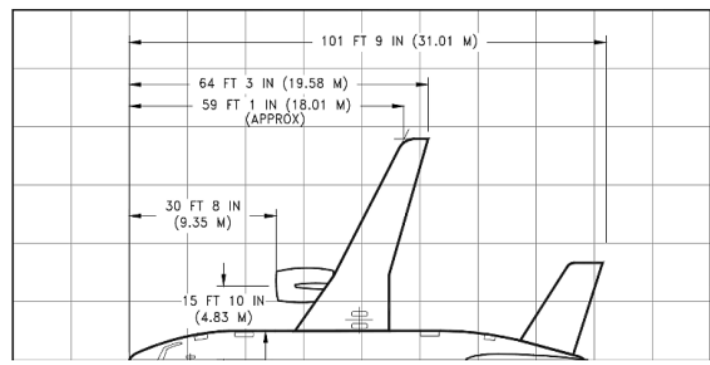

Gambar 2.1 Geometri Sayap B737-500 ${ }^{[11]}$

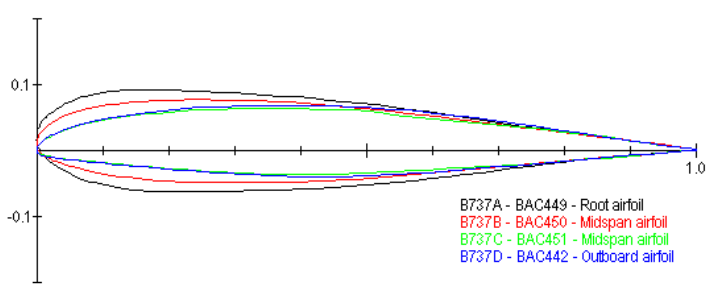

Gambar 2.2 Jenis Airfoil pesawat Boeing $737-500^{[11]}$

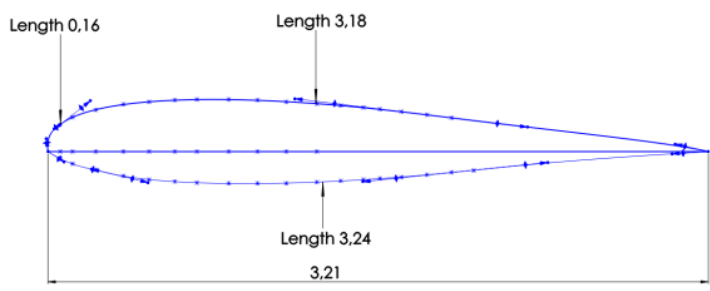

Gambar 2.3 Permodelan Airfoil Basic BAC450 dengan panjang chord $3,21 \mathrm{~m}$ 


\subsection{Dimensi Sayap}

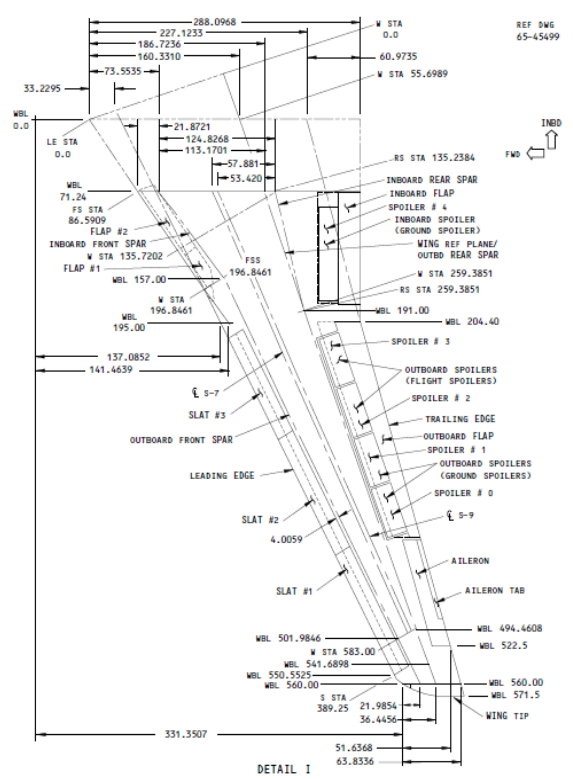

Gambar 2.4 Dimensi Sayap B737-500 ${ }^{[11]}$

\section{HASIL DAN PEMBAHASAN}

\subsection{Perhitungan Berat Sayap Pesawat B737-500}

Dimensi sayap B737-500 dapat dilihat pada Gambar 2.3, sedangkan gambar dimensi yang digambar dengan Solidwork ditampilkan pada Gambar 3.1.

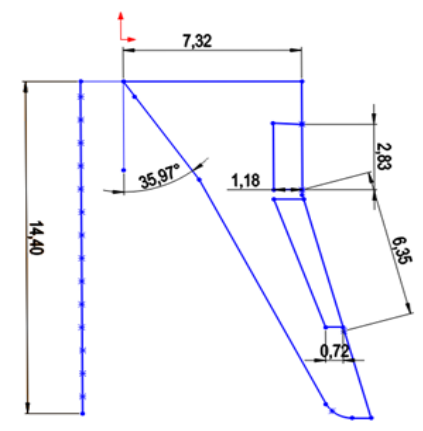

Gambar 3.1 Dimensi Sayap memakai Software Solidwork

Untuk dapat mengetahui berat sayap dapat dihitung menggunakan Persamaan Wing Weight dengan sudut $16^{\circ}$ saat posisi pesawat saat climb, sebagai berikut :

$$
W_{w}=W_{W_{\text {basic }}}+1.2\left(W_{\text {hld }}+W_{\text {sp }}\right)
$$

Dimana :

$$
\begin{aligned}
& W_{W_{\text {basic }}}=\left(4,58 \times 10^{-3}\right) \times k_{n o} k_{\lambda} k_{e} k_{u c} k_{s t} \times \\
& {\left[k_{b} n_{u l t}\left(W_{\text {des }}-0.8 W_{w}\right)\right]^{0.55} \times} \\
& b^{1.675}(t / c)_{r}^{-0.45}\left(\cos \Lambda_{\frac{1}{2}}\right)^{-1.325}
\end{aligned}
$$

$=\left(4,58 \times 10^{-3}\right) \times 1,2571 \times 1,089 \times$

$0,95 \times 1 \times 1,073 \times[1 \times 6(46490 \times$

$0,8 W w)]^{0.55} \times(28,8)^{1.675} \times$

$(0,154)^{-0.45} \times(0,906)^{-1.325}$

$=4,7061 \times[278940-4,8 W w]^{0.55}$

Setelah mengetahui wing weight basic, lalu tentukan Weight Trailing Edge Flap.

$$
\begin{aligned}
& \frac{W_{t e f}}{S_{f}}=2,706 \times k_{f}\left(S_{f} b_{f s}\right)^{3 / 16} \times \\
& {\left[\left(\frac{V_{l f}}{100}\right)^{2} \frac{\sin \delta_{f} \cos \Lambda_{f}}{(t / c)_{f}}\right]^{3 / 4}}
\end{aligned}
$$

$\frac{W_{t e f}}{7,91}=2,706 \times[1,45 \times 1,25](7,91 \times$

$9,18)^{\frac{3}{16}} \times\left[\left(\frac{150}{100}\right)^{2} \frac{\sin 40 \cos 12,25}{0.18}\right]^{\frac{3}{4}}$

$W_{\text {tef }}=401,776 \mathrm{~kg}$

Setelah menetukan $\mathrm{W}_{\text {tef, lalu dapat }}$ ditentukan Weight High-Lift Device.

$$
\begin{aligned}
& W_{\text {hld }}=W_{\text {tef }}+W_{\text {lef }} \\
& W_{\text {hld }}=401,776+218,86 \\
& W_{\text {hld }}=\mathbf{6 2 0 , 6 3 6 \mathrm { kg }}
\end{aligned}
$$

Setelah mendapatkan nilai dari persaamaan-persamaan di atas, maka dapat dimasukan persamaan

$$
\begin{aligned}
& W_{w}=W_{W_{\text {basic }}}+1.2\left(W_{\text {hld }}+W_{\text {sp }}\right) \\
& W_{w}=4,7061 \times(278940-4,8 W w)^{0,55}+ \\
& 1,2(620,636+0,015 W w) \\
& W_{w}=31343,661 \mathrm{~N}
\end{aligned}
$$

\subsection{Perhitungan Distribusi Berat Sayap}

Perhitungan yang dilakukan hanya menggunakan 1 sayap dan wing area pun hanya memakai 1 bagian sayap.

$$
\begin{aligned}
\frac{1}{2} \text { Berat sayap } & =\frac{\text { Berat Seluruhnya }}{2} \times \cos \left(16^{\circ}\right) \\
& =15671,8305 \mathrm{~N}
\end{aligned}
$$

Pembagian wing section pada setiap sayap yang dapat dilihat pada Gambar 3.2. 


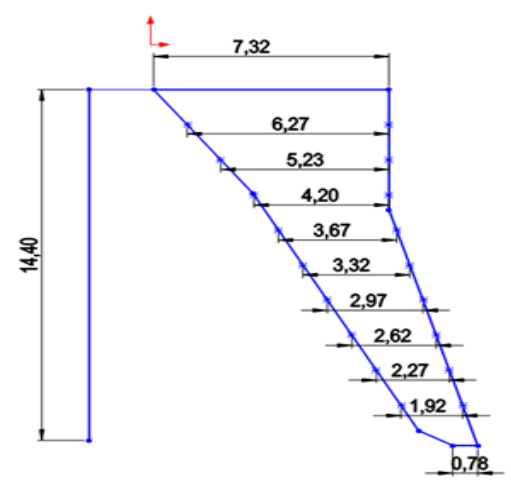

Gambar 3.2 Wing Section

Wing Section $1=$ Area $\times$ Weight/Area

$$
\begin{aligned}
& =9,785 \times 286,462 \\
& =2802,97 \mathrm{~N}
\end{aligned}
$$

\begin{tabular}{|c|c|c|c|c|c|}
\hline $\begin{array}{l}\text { Wing } \\
\text { Section }\end{array}$ & $\begin{array}{c}\text { Csec } \\
\text { (m) }\end{array}$ & $\begin{array}{c}\text { AREA } \\
\left(\mathrm{m}^{2}\right)\end{array}$ & $\begin{array}{c}\text { Weight/A } \\
\left(\mathrm{N} / \mathrm{m}^{2}\right)\end{array}$ & $\begin{array}{l}\text { WEIGHT DIST } \\
\text { (N) UDARA }\end{array}$ & $\begin{array}{l}\text { WEIGHT DIST } \\
\text { (N) DARAT }\end{array}$ \\
\hline 1 & 7.32 & 9.785 & 286.462 & 2802.97 & 2915.93 \\
\hline 2 & 6.27 & 8.280 & 286.462 & 2371.90 & 2467.49 \\
\hline 3 & 5.23 & 6.790 & 286.462 & 1944.96 & 2023.34 \\
\hline 4 & 4.2 & 5.666 & 286.462 & 1623.21 & 1688.62 \\
\hline 5 & 3.67 & 5.033 & 286.462 & 1441.70 & 1499.80 \\
\hline 6 & 3.32 & 4.529 & 286.462 & 1297.33 & 1349.61 \\
\hline 7 & 2.97 & 4.025 & 286.462 & 1152.95 & 1199.41 \\
\hline 8 & 2.62 & 3.521 & 286.462 & 1008.57 & 1049.22 \\
\hline 9 & 2.27 & 3.017 & 286.462 & 864.20 & 899.02 \\
\hline 10 & 1.92 & 1.944 & 286.462 & 556.88 & 579.32 \\
\hline 11 & 0.78 & 0.000 & 286.462 & 0 & 0.00 \\
\hline \multicolumn{4}{|c|}{ TOTAL } & 15064.67 & 15671.77 \\
\hline
\end{tabular}

Tabel 3.1 Weight Distribution

\subsection{Distribusi Berat Fuel Per Section}

Pembagian section pada tangki dibagi menjadi 10 bagian pada tangki bahan bakar. Dengan berat bahan bakar $76137,36514 \mathrm{~N}$ dan luas tangki bahan bakar pada satu bagian sayap adalah $21,24 \mathrm{~m}^{2}$ dapat diperoleh weight/Area $3584,622 \mathrm{~N} / \mathrm{m}^{2}$.

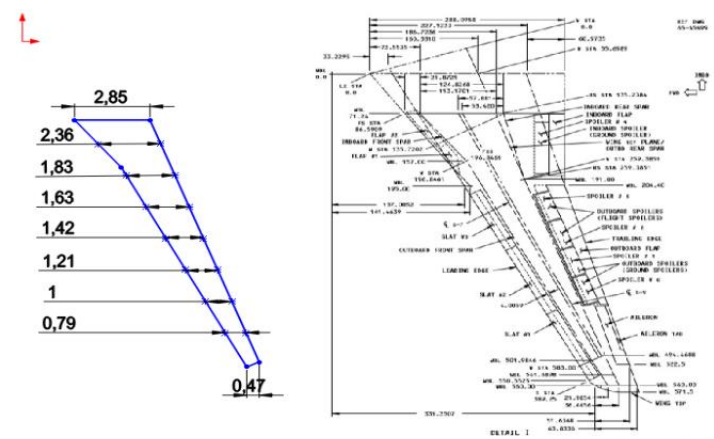

Gambar 3.3 Fuel Tank Section ${ }^{[13]}$
Wing Section 1 = Area $\times$ weight/area

$$
\begin{aligned}
& =4,104 \times 3584,622 \\
& =14711,29 \mathrm{~N}
\end{aligned}
$$

\begin{tabular}{|c|c|c|c|c|}
\hline $\begin{array}{l}\text { Wing } \\
\text { Section }\end{array}$ & $\begin{array}{c}\text { weight A } \\
\left(\mathrm{N} / \mathrm{m}^{2}\right)\end{array}$ & $\begin{array}{l}\text { Csec } \\
\text { (m) }\end{array}$ & $\begin{array}{l}\text { Area } \\
\left(\mathrm{m}^{2}\right)\end{array}$ & $\begin{array}{c}\text { FUEL W } \\
\text { DISTRIBUTION } \\
\text { (N) }\end{array}$ \\
\hline 1 & 3584,622 & 2,85 & 4,10 & 14711,29 \\
\hline 2 & 3584,622 & 2,85 & 3,75 & 13446,63 \\
\hline 3 & 3584,622 & 2,36 & 3,02 & 10814,09 \\
\hline 4 & 3584,622 & 1,83 & 2,49 & 8930,01 \\
\hline 5 & 3584,622 & 1,63 & 2,20 & 7871,83 \\
\hline 6 & 3584,622 & 1,42 & 1,89 & 6787,84 \\
\hline 7 & 3584,622 & 1,21 & 1,59 & 5703,85 \\
\hline 8 & 3584,622 & 1 & 1,29 & 4619,86 \\
\hline 9 & 3584,622 & 0,79 & 0,91 & 3251,97 \\
\hline 10 & 3584,622 & 0,47 & 0,00 & 0 \\
\hline \multicolumn{3}{|c|}{ TOTAL } & 21,24 & 76137,36514 \\
\hline
\end{tabular}

Tabel 3.2 Fuel Weight Distribution

\subsection{Perhitungan Distribusi Lift}

- Mencari nilai $C_{1}, C_{2}, C_{3}$ dan $C_{4}$

$$
\frac{2 \pi A}{C l_{\alpha} \cos A_{0,25}}=\frac{2 \times 3,14 \times 9,17}{5,727 \times \cos 25}=11,094
$$

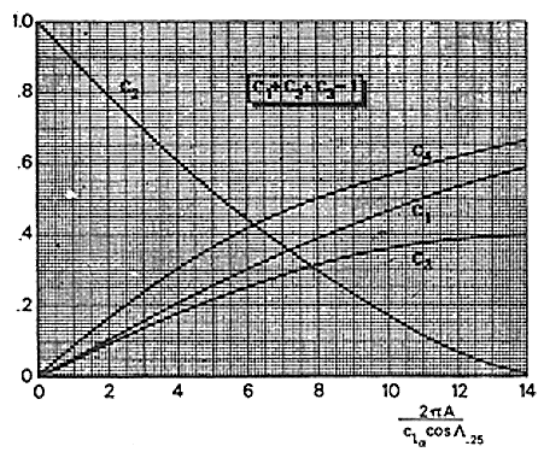

Gambar 3.4 Diagram diedrich method ${ }^{[9]}$

Nilai $C_{1}=0,5 ; C_{2}=0,1 ; C_{3}=0,39$, dan $C_{4}=$ 0,6

- Mencari nilai $\bar{C}$

$\bar{C}$ merupakan fungsi dari span per aspek ratio sehingga dapat dihitung dengan rumus :

$$
C=b / A=28,8 \mathrm{~m} / 9,17=3,1406 \mathrm{~m}
$$

- Mencari nilai $\eta$

$\eta$ merupakan non-dimentional parameter spanwise station yang dapat dihitung dengan rumus :

$$
\eta=\frac{y}{b / 2}=\frac{0 m}{28,8 m / 2}=0(\text { section } 1)
$$


Tabel 3.3 Wing Section

\begin{tabular}{|c|c|c|}
\hline $\begin{array}{c}\text { wing } \\
\text { section }\end{array}$ & $\begin{array}{c}\text { jarak } \\
\mathbf{y}(\mathbf{m})\end{array}$ & $\eta$ \\
\hline 1 & 0 & 0 \\
\hline 2 & 1.44 & 0.1 \\
\hline 3 & 2.88 & 0.2 \\
\hline 4 & 4.32 & 0.3 \\
\hline 5 & 5.76 & 0.4 \\
\hline 6 & 7.2 & 0.5 \\
\hline 7 & 8.64 & 0.6 \\
\hline 8 & 10.08 & 0.7 \\
\hline 9 & 11.52 & 0.8 \\
\hline 10 & 12.96 & 0.9 \\
\hline 11 & 14.4 & 1 \\
\hline
\end{tabular}

- Mencari nilai $f$

Nilai f ditentukan dengan melihat nilai $\eta$ $=0$ dan $\Lambda \beta=26,968$ sehingga dapat dilihat diagramnya seperti pada gambar berikut :

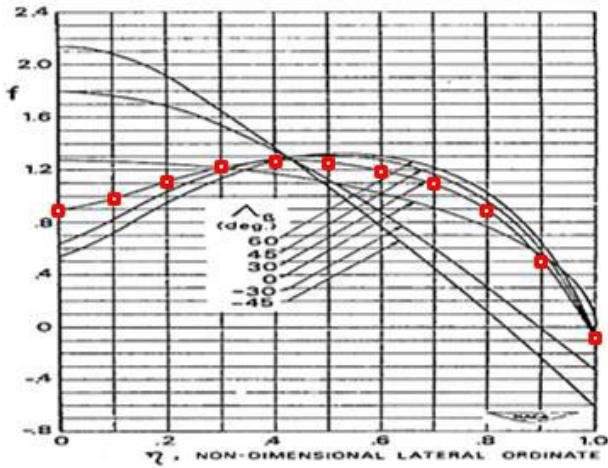

Gambar 3.5 Nilai fungsi f pada setiap section sayap ${ }^{[9]}$

- $\quad$ Mencari $\beta$

$\beta=\sqrt{1-M^{2}}=\sqrt{1-(0,375)^{2}}=$ 0,9270

- Mencari

$E=1+\frac{2 \lambda}{A(1+\lambda)}=1+\frac{2 \times 0,24}{9,17(1+0,24)}=$ 1,0422

- $\quad$ Mencari $\Lambda_{\beta}$

$$
\Lambda_{\beta}=\Lambda_{1 / 4} / \beta=25 / 0,9270=26,9676^{\circ}
$$

- Mencari $\varepsilon$

$$
\varepsilon=\eta \cdot \varepsilon_{t}=0,0 \times 0,05236 \mathrm{rad}=0
$$

- Mencari $\alpha_{0,1}$
Nilai $\alpha_{0,1}$ ditentukan dari berdasarkan twist lokal pada kondisi $\mathrm{CL}=0$ dimana asumsi nilai $\alpha_{0,1}=-2^{\circ}(-0,0349 \mathrm{rad})$.

- Mencari $L_{\alpha}$

$$
\begin{aligned}
& L_{\alpha}=C_{1} \cdot \frac{C_{s e c}}{\mathrm{C}}+C_{2} \cdot \frac{4}{\pi} \cdot \sqrt{1-\eta^{2}}+ \\
& C_{3} \cdot f=1,643743
\end{aligned}
$$

Tabel 3.4 Nilai $\mathrm{L}_{a}$

\begin{tabular}{|c|c|c|c|c|}
\hline $\begin{array}{c}\text { wing } \\
\text { section }\end{array}$ & $\begin{array}{c}\mathbf{C}_{\text {sec }} \\
(\mathbf{m})\end{array}$ & $\eta$ & $\mathbf{f}$ & $\mathrm{La}$ \\
\hline 1 & 7.32 & 0 & 0.9 & 1.643743 \\
\hline 2 & 6.27 & 0.1 & 0.98 & 1.507143 \\
\hline 3 & 5.23 & 0.2 & 1.11 & 1.390338 \\
\hline 4 & 4.2 & 0.3 & 1.21 & 1.262067 \\
\hline 5 & 3.67 & 0.4 & 1.28 & 1.200223 \\
\hline 6 & 3.32 & 0.5 & 1.25 & 1.12637 \\
\hline 7 & 2.97 & 0.6 & 1.19 & 1.038839 \\
\hline 8 & 2.62 & 0.7 & 1.09 & 0.933181 \\
\hline 9 & 2.27 & 0.8 & 0.9 & 0.78882 \\
\hline 10 & 1.92 & 0.9 & 0.5 & 0.556194 \\
\hline 11 & 0.78 & 1 & -0.1 & 0.085177 \\
\hline
\end{tabular}

- Mencari $L_{b}$

$$
\begin{gathered}
L_{b}=\beta \cdot E\left[L_{a} \cdot C_{4} \cdot\right. \\
\Lambda_{\beta} \cdot \\
\left.\cos \left(\frac{\varepsilon}{\varepsilon_{t}}+\alpha_{0,1}\right)\right]=-0,029645
\end{gathered}
$$

Tabel 3.5 Nilai $L_{b}$

\begin{tabular}{|c|c|c|c|}
\hline $\begin{array}{c}\text { wing } \\
\text { section }\end{array}$ & $\boldsymbol{\varepsilon}$ & $\mathbf{L a}$ & $\mathbf{L}_{\mathbf{b}}$ \\
\hline 1 & 0 & 1.643743 & -0.02965 \\
\hline 2 & 0.005 & 1.507143 & 0.050687 \\
\hline 3 & 0.01 & 1.390338 & 0.118591 \\
\hline 4 & 0.015 & 1.262067 & 0.172856 \\
\hline 5 & 0.02 & 1.200223 & 0.226396 \\
\hline 6 & 0.026 & 1.12637 & 0.27066 \\
\hline 7 & 0.031 & 1.038839 & 0.3033 \\
\hline 8 & 0.036 & 0.933181 & 0.320665 \\
\hline 9 & 0.041 & 0.78882 & 0.311814 \\
\hline 10 & 0.047 & 0.556194 & 0.248595 \\
\hline 11 & 0.052 & 0.085177 & 0.042471 \\
\hline
\end{tabular}

- Mencari $C l$ tiap section

$$
\begin{aligned}
& C_{l}=\frac{\mathrm{C}}{C_{\text {sec }}}\left(L_{a} \cdot C_{L}+\frac{\varepsilon_{t} a_{0}}{E} L_{b}\right) \\
& C_{l_{1}}=0,523051
\end{aligned}
$$


Tabel 3.6 Nilai Cl tiap section

\begin{tabular}{|c|c|c|}
\hline wing section & $\mathbf{C}_{\text {sec }}(\mathbf{m})$ & $\mathbf{C l}_{\text {sec }}$ \\
\hline 1 & 7.32 & 0.523051 \\
\hline 2 & 6.27 & 0.559829 \\
\hline 3 & 5.23 & 0.619062 \\
\hline 4 & 4.2 & 0.699673 \\
\hline 5 & 3.67 & 0.761386 \\
\hline 6 & 3.32 & 0.789767 \\
\hline 7 & 2.97 & 0.814132 \\
\hline 8 & 2.62 & 0.828924 \\
\hline 9 & 2.27 & 0.808628 \\
\hline 10 & 1.92 & 0.674014 \\
\hline 11 & 0.78 & 0.25405 \\
\hline
\end{tabular}

\subsection{Hasil Distribusi Lift}

Nilai distribusi lift tiap section didapatkan dari persamaan lift standar dimana :

$$
\begin{aligned}
& L=\frac{1}{2} \rho \cdot v^{2} \cdot C_{L} \cdot S_{\text {wing }} \\
& L_{1}=38918,66 \mathrm{~N}
\end{aligned}
$$

Secara keseluruhan nilai distribusi Lift di tiap section dapat dilihat pada Tabel 3.7.

Tabel 3.7 Nilai lift tiap section

\begin{tabular}{|c|c|r|r|}
\hline $\begin{array}{c}\text { wing } \\
\text { section }\end{array}$ & $\mathbf{C}_{\text {sec }}(\mathbf{m})$ & \multicolumn{1}{c|}{$\mathrm{Cl}_{\text {sec }}$} & \multicolumn{1}{c|}{$\mathrm{L}_{\text {sec }}(\mathbf{N})$} \\
\hline 1 & 7.32 & 0.523051 & 37411.08 \\
\hline 2 & 6.27 & 0.559829 & 33883.61 \\
\hline 3 & 5.23 & 0.619062 & 30724.32 \\
\hline 4 & 4.2 & 0.699673 & 28980.55 \\
\hline 5 & 3.67 & 0.761386 & 28010.36 \\
\hline 6 & 3.32 & 0.789767 & 26144.87 \\
\hline 7 & 2.97 & 0.814132 & 23952.08 \\
\hline 8 & 2.62 & 0.828924 & 21333.4 \\
\hline 9 & 2.27 & 0.808628 & 17831.98 \\
\hline 10 & 1.92 & 0.674014 & 9577.87 \\
\hline 11 & 0.78 & 0.25405 & 0 \\
\hline
\end{tabular}

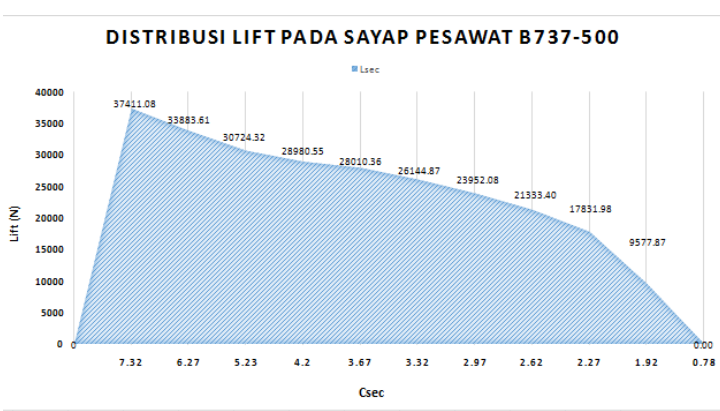

Gambar 3.6 Diagram distribusi lift

\subsection{Analisis dan Perbandingan}

Dari hasil di atas diperoleh perbandingan distribusi berat fuel pada saat di darat dan di udara. Pada setiap kondisi diaplikasikan ke tiga sistem pentrasferan fuel, untuk mengetahui selisih distribusi berat fuel sebelum di transfer dan sesudah di transfer.

\section{a. Sistem Fuel Transfer Constant}

Berdasarkan Tabel 3.8 dan 3.9, selisih moment saat di darat dan di udara sebelum transfer adalah 2001208,45 N.m dan sesudah transfer adalah 1961074,93 N.m. Sedangkan, tinggi defleksi saat di darat dan di udara sebelum transfer adalah $0,050972 \mathrm{~m}$ dan sesudah transfer adalah $0,049332 \mathrm{~m}$. Dengan diketahui selisih moment dan tinggi defleksi pada saat sebelum dan sesudah transfer pada kondisi di udara dan darat adalah 40134,53 N.m dan 0,001639 m.

\section{b. Sistem Fuel Transfer Linier}

Berdasarkan Tabel $\mathbf{3 . 1 0}$ dan $\mathbf{3 . 1 1}$, selisih moment saat di darat dan di udara sebelum transfer adalah 2001206,45 N.m dan sesudah transfer adalah 1953149,63 N.m. Sedangkan, tinggi defleksi saat di darat dan di udara sebelum transfer adalah $0,050972 \mathrm{~m}$ dan sesudah transfer adalah $0,048967 \mathrm{~m}$. Dengan diketahui selisih moment dan tinggi defleksi pada saat sebelum dan sesudah transfer pada kondisi di udara dan darat adalah 48059,53 N.m dan 0,002005 m. 
Tabel 3. 8 Moment Pesawat ketika Fuel Transfer Constant Pada saat di Udara

\begin{tabular}{|c|c|c|c|c|c|c|c|c|c|}
\hline \multicolumn{2}{|c|}{ Nett Loading $(\mathrm{N})$} & \multicolumn{2}{c|}{ Shear $(\mathrm{N} . \mathrm{m})$} & \multicolumn{2}{c|}{ Bending Momen $\left(\mathrm{N} . \mathrm{m}^{2}\right)$} & \multicolumn{2}{c|}{ Sudut Defleksi $\theta$} & \multicolumn{2}{c|}{ Tinggi Defleksi 'w' $(\mathrm{m})$} \\
\hline Non & Transfer & Non & Transfer & Non & Transfer & Non & Transfer & Non & Transfer \\
\hline 23537.24 & 24027.24 & -222412.88 & -222060.08 & 1450574.81 & 1430507.55 & 0.000000 & 0.000000 & 0.000000 & 0.000000 \\
\hline 21392.54 & 21882.54 & -190063.44 & -189005.04 & 1153591.86 & 1134540.66 & 0.000226 & 0.000223 & 0.000163 & 0.000160 \\
\hline 1374.50 & 1864.50 & -173671.18 & -171907.18 & 891702.93 & 874683.86 & 0.000572 & 0.000562 & 0.000737 & 0.000726 \\
\hline 20637.13 & 21127.13 & -157822.81 & -155353.21 & 653027.26 & 639056.38 & 0.001149 & 0.001128 & 0.001976 & 0.001942 \\
\hline 20644.77 & 20644.77 & -128099.85 & -125277.45 & 447162.95 & 437002.31 & 0.002006 & 0.001966 & 0.004248 & 0.004170 \\
\hline 19739.40 & 19249.40 & -99023.25 & -96553.65 & 283634.33 & 277283.93 & 0.002941 & 0.002880 & 0.007810 & 0.007660 \\
\hline 18506.73 & 18016.73 & -71486.03 & -69722.03 & 160867.64 & 157565.44 & 0.003809 & 0.003729 & 0.012670 & 0.012418 \\
\hline 16848.18 & 16358.18 & -46030.49 & -44972.09 & 76255.75 & 74985.67 & 0.004549 & 0.004455 & 0.018688 & 0.018310 \\
\hline 14520.54 & 14030.54 & -23445.02 & -23092.22 & 26233.38 & 25979.36 & 0.005093 & 0.004991 & 0.025630 & 0.025111 \\
\hline 9020.99 & 9020.99 & -6495.11 & -6495.11 & 4676.48 & 4676.48 & 0.005392 & 0.005287 & 0.033179 & 0.032511 \\
\hline 0.00 & 0.00 & 0.00 & 0.00 & 0.00 & 0.00 & 0.005480 & 0.005375 & 0.041007 & 0.040187 \\
\hline
\end{tabular}

Tabel 3. 9 Moment Pesawat ketika Fuel Transfer Constant Pada saat di Darat

\begin{tabular}{|c|c|c|c|c|c|c|c|c|c|}
\hline \multicolumn{2}{|c|}{ Nett Loading $(\mathrm{N})$} & \multicolumn{2}{c|}{ Shear $(\mathrm{N} . \mathrm{m})$} & \multicolumn{2}{c|}{ Bending Momen $\left(\mathrm{N} . \mathrm{m}^{2}\right)$} & \multicolumn{2}{c|}{ Sudut Defleksi $\theta$} & \multicolumn{2}{c|}{ Tinggi Defleksi 'w' $(\mathrm{m})$} \\
\hline Non & Transfer & Non & Transfer & Non & Transfer & Non & Transfer & Non & Transfer \\
\hline-14432.95 & -14922.95 & 125751.96 & 125399.16 & -550634.64 & -530567.38 & 0.000000 & 0.000000 & 0.000000 & 0.000000 \\
\hline-12994.45 & -13484.45 & 106004.23 & 104945.83 & -383770.19 & -364718.99 & -0.000081 & -0.000078 & -0.000059 & -0.000056 \\
\hline-29756.16 & -30246.16 & 75223.78 & 73459.78 & -253286.02 & -236266.95 & -0.000189 & -0.000179 & -0.000253 & -0.000241 \\
\hline-8679.66 & -9169.66 & 47549.99 & 45080.39 & -164888.91 & -150918.03 & -0.000344 & -0.000323 & -0.000637 & -0.000603 \\
\hline-7662.42 & -7662.42 & 35783.69 & 32961.29 & -104888.65 & -94728.01 & -0.000555 & -0.000515 & -0.001284 & -0.001207 \\
\hline-6663.60 & -6173.60 & 25468.95 & 22999.35 & -60786.75 & -54436.35 & -0.000768 & -0.000707 & -0.002237 & -0.002087 \\
\hline-5664.79 & -5174.79 & 16592.51 & 14828.51 & -30502.49 & -27200.28 & -0.000948 & -0.000868 & -0.003473 & -0.003221 \\
\hline-4665.97 & -4175.97 & 9154.37 & 8095.97 & -11964.74 & -10694.66 & -0.001081 & -0.000987 & -0.004933 & -0.004556 \\
\hline-3444.89 & -2954.89 & 3314.55 & 2961.75 & -2987.12 & -2733.10 & -0.001161 & -0.001059 & -0.006548 & -0.006029 \\
\hline-579.32 & -579.32 & 417.11 & 417.11 & -300.32 & -300.32 & -0.001193 & -0.001088 & -0.0008243 & -0.007574 \\
\hline 0.00 & 0.00 & 0.00 & 0.00 & 0.00 & 0.00 & -0.001199 & -0.001094 & -0.009965 & -0.009145 \\
\hline
\end{tabular}

Tabel 3. 10 Moment Pesawat ketika Fuel Transfer Linier Pada saat di Udara

\begin{tabular}{|c|c|c|c|c|c|c|c|c|c|}
\hline \multicolumn{2}{|c|}{ Nett Loading $(\mathrm{N})$} & \multicolumn{2}{c|}{ Shear $(\mathrm{N} . \mathrm{m})$} & \multicolumn{2}{c|}{ Bending Momen $\left(\mathrm{N} . \mathrm{m}^{2}\right)$} & \multicolumn{2}{c|}{ Sudut Defleksi $\theta$} & \multicolumn{2}{c|}{ Tinggi Defleks ' $\mathbf{w}^{\prime}(\mathrm{m})$} \\
\hline Non & Transfer & Non & Transfer & Non & Transfer & Non & Transfer & Non & Transfer \\
\hline 23537.24 & 24223.24 & -222412.88 & -221918.96 & 1450574.81 & 1426544.90 & 0.000000 & 0.000000 & 0.000000 & 0.000000 \\
\hline 21392.54 & 21980.54 & -190063.44 & -188652.24 & 1153591.86 & 1130933.63 & 0.000226 & 0.000222 & 0.000163 & 0.000160 \\
\hline 1374.50 & 1864.50 & -173671.18 & -171483.82 & 891702.93 & 871635.67 & 0.000572 & 0.000560 & 0.000737 & 0.000723 \\
\hline 20637.13 & 21029.13 & -157822.81 & -155000.41 & 653027.26 & 636567.03 & 0.001149 & 0.001124 & 0.001976 & 0.001936 \\
\hline 20644.77 & 20644.77 & -128099.85 & -124995.21 & 447162.95 & 434970.19 & 0.002006 & 0.001959 & 0.004248 & 0.004156 \\
\hline 19739.40 & 19347.40 & -99023.25 & -96200.85 & 283634.33 & 275709.03 & 0.002941 & 0.002868 & 0.007810 & 0.007632 \\
\hline 18506.73 & 18016.73 & -71486.03 & -69298.67 & 160867.64 & 156549.37 & 0.003809 & 0.003712 & 0.012670 & 0.012369 \\
\hline 16848.18 & 16260.18 & -46030.49 & -44619.29 & 76255.75 & 74528.44 & 0.004549 & 0.004433 & 0.018688 & 0.018234 \\
\hline 14520.54 & 13834.54 & -23445.02 & -22951.10 & 26233.38 & 25877.75 & 0.005093 & 0.004966 & 0.025630 & 0.025001 \\
\hline 9020.99 & 9020.99 & -6495.11 & -6495.11 & 4676.48 & 4676.48 & 0.005392 & 0.005261 & 0.033179 & 0.032365 \\
\hline 0.00 & 0.00 & 0.00 & 0.00 & 0.00 & 0.00 & 0.005480 & 0.005350 & 0.041007 & 0.040005 \\
\hline
\end{tabular}


Tabel 3. 11 Pada saat di Darat Moment Pesawat ketika Fuel Transfer Linier

\begin{tabular}{|c|c|c|c|c|c|c|c|c|c|}
\hline \multicolumn{2}{|c|}{ Nett Loading (N) } & \multicolumn{2}{|c|}{ Shear (N.m) } & \multicolumn{2}{|c|}{ Bending Momen (N.m²) } & \multicolumn{2}{|c|}{ Sudut Defleksi $\theta$} & \multicolumn{2}{|c|}{ Tinggi Defleksi 'w' (m) } \\
\hline Non & Transfer & Non & Transfer & Non & Transfer & Non & Transfer & Non & Transfer \\
\hline-14432.95 & -15118.95 & 125751.96 & 125258.04 & -550634.64 & -526604.73 & 0.000000 & 0.000000 & 0.000000 & 0.000000 \\
\hline-12994.45 & -13582.45 & 106004.23 & 104593.03 & -383770.19 & -361111.96 & -0.000081 & -0.000077 & -0.000059 & -0.000056 \\
\hline-29756.16 & -30246.16 & 75223.78 & 73036.42 & -253286.02 & -233218.76 & -0.000189 & -0.000178 & -0.000253 & -0.000239 \\
\hline-8679.66 & -9071.66 & 47549.99 & 44727.59 & -164888.91 & -148428.67 & -0.000344 & -0.000319 & -0.000637 & -0.000597 \\
\hline-7662.42 & .7662 .42 & 35783.69 & 32679.05 & -104888.65 & -92695.89 & -0.000555 & -0.000508 & -0.001284 & -0.001192 \\
\hline-6663.60 & -6271.60 & 25468.95 & 22646.55 & -60786.75 & -52861.45 & -0.000768 & -0.000695 & -0.002237 & -0.002059 \\
\hline-5664.79 & -5174.79 & 16592.51 & 14405.15 & -30502.49 & -26184.22 & -0.000948 & -0.000851 & -0.003473 & -0.003172 \\
\hline-4665.97 & -4077.97 & 9154.37 & 7743.17 & -11964.74 & -10237.43 & -0.001081 & -0.000965 & -0.004933 & -0.004479 \\
\hline-3444.89 & -2758.89 & 3314.55 & 2820.63 & -2987.12 & -2631.49 & -0.001161 & -0.001034 & -0.006548 & -0.005919 \\
\hline-579.32 & -579.32 & 417.11 & 417.11 & -300.32 & -300.32 & -0.001193 & -0.001062 & -0.008243 & -0.007428 \\
\hline 0.00 & 0.00 & 0.00 & 0.00 & 0.00 & 0.00 & -0.001199 & -0.001068 & -0.009965 & -0.008962 \\
\hline
\end{tabular}

Tabel 3. 12 Moment Pesawat ketika Maximum Fuel Transfer Pada saat di Udara

\begin{tabular}{|c|c|c|c|c|c|c|c|c|c|}
\hline \multicolumn{2}{|c|}{ Nett Loading $(\mathrm{N})$} & \multicolumn{2}{|c|}{ Shear $(\mathrm{N} . \mathrm{m})$} & \multicolumn{2}{c|}{ Bending Momen $\left(\mathrm{N} . \mathrm{m}^{2}\right)$} & \multicolumn{2}{c|}{ Sudut Defleksi $\theta$} & \multicolumn{2}{c|}{ Tinggi Defleksi' $\mathrm{w}^{\prime}(\mathrm{m})$} \\
\hline Non & Transfer & Non & Transfer & Non & Transfer & Non & Transfer & Non & Transfer \\
\hline 23537.24 & 25216.93 & -222412.88 & -221203.50 & 1450574.81 & 1399200.21 & 0.000000 & 0.000000 & 0.000000 & 0.000000 \\
\hline 21392.54 & 22804.00 & -190063.44 & -186628.43 & 1153591.86 & 1105561.23 & 0.000226 & 0.000218 & 0.000163 & 0.000157 \\
\hline 1374.50 & 2517.72 & -173671.18 & -168396.80 & 891702.93 & 8499943.07 & 0.000572 & 0.000548 & 0.000737 & 0.000708 \\
\hline 20637.13 & 21441.85 & -157822.81 & -151145.91 & 653027.26 & 619872.32 & 0.001149 & 0.001097 & 0.001976 & 0.001892 \\
\hline 20644.77 & 20644.77 & -128099.85 & -120843.55 & 447162.95 & 424039.91 & 0.002006 & 0.001911 & 0.004248 & 0.004057 \\
\hline 19739.40 & 18059.70 & -99023.25 & -92976.33 & 283634.33 & 270089.60 & 0.002941 & 0.002799 & 0.007810 & 0.007448 \\
\hline 18506.73 & 17095.28 & -.71486 .03 & -67664.75 & 160867.64 & 154428.02 & 0.003809 & 0.003626 & 0.012670 & 0.012074 \\
\hline 16848.18 & 15704.96 & -46030.49 & -44048.58 & 76255.75 & 73994.43 & 0.004549 & 0.004340 & 0.018688 & 0.017809 \\
\hline 14520.54 & 13715.82 & -23445.02 & -22865.62 & 26233.38 & 25816.21 & 0.005093 & 0.004869 & 0.025630 & 0.024440 \\
\hline 9020.99 & 9020.99 & -6495.11 & -6495.11 & 4676.48 & 4676.48 & 0.005392 & 0.005164 & 0.033179 & 0.031663 \\
\hline 0.00 & 0.00 & 0.00 & 0.00 & 0.00 & 0.00 & 0.005480 & 0.005252 & 0.041007 & 0.039162 \\
\hline
\end{tabular}

Tabel 3. 13 Moment Pesawat ketika Maximum Fuel Transfer Pada saat di Darat

\begin{tabular}{|c|c|c|c|c|c|c|c|c|c|}
\hline \multicolumn{2}{|c|}{ Nett Loading (N) } & \multicolumn{2}{|c|}{ Shear (N.m) } & \multicolumn{2}{|c|}{ Bending Momen (N.m²) } & \multicolumn{2}{|c|}{ Sudut Defleksi $\theta$} & \multicolumn{2}{|c|}{ Tinggi Defleksi 'w' (m) } \\
\hline Non & Transfer & Non & Transfer & Non & Transfer & Non & Transfer & Non & Transfer \\
\hline-14432.95 & $-18220,07$ & 125751,96 & 123025.23 & .550634 .64 & $-424746,03$ & 0.000000 & 0.000000 & 0.000000 & 0.000000 \\
\hline$-12994,45$ & $-16456,01$ & 106004.23 & 98058.45 & -383770.19 & -265565.78 & $-0,000081$ & $-0,000060$ & -0.000059 & -0.000043 \\
\hline .29756 .16 & $-32540,03$ & 75223.78 & 62781.30 & $.253286,02$ & $-149761,16$ & $-0,000189$ & -0.000130 & $-0,000253$ & $-0,000180$ \\
\hline-8679.66 & -10978.50 & 47549.99 & 31447.96 & -164888.91 & -81916.09 & -0.000344 & $-0,000216$ & -0.000637 & -0.000429 \\
\hline $.7662,42$ & $.7662,42$ & 35783.69 & 18026.49 & -104888.65 & -46294.48 & -0.000555 & -0.000316 & -0.001284 & -0.000812 \\
\hline .6663 .60 & -2876.49 & 25468.95 & 10438.48 & .60786 .75 & -25799.70 & $-0,000768$ & $-0,000409$ & $-0,002237$ & -0.001335 \\
\hline-5664.79 & -2203.23 & 16592.51 & 6781.08 & $-30502,49$ & $-13401,62$ & $-0,000948$ & -0.000486 & -0.003473 & $-0,001980$ \\
\hline-4665.97 & $-1882,10$ & 9154.37 & 3839.65 & $-11964,74$ & $.5754,69$ & -0.001081 & $-0,000546$ & $-0,004933$ & -0.002723 \\
\hline-3444.89 & -1146.05 & 3314.55 & 1659.38 & $.2987,12$ & -1795.39 & -0.001161 & $-0,000586$ & -0.006548 & -0.003538 \\
\hline-579.32 & -579.32 & 417.11 & 417.11 & $-300,32$ & $-300,32$ & -0.001193 & -0.000607 & -0.008243 & -0.004397 \\
\hline 0.00 & 0,00 & 0.00 & 0.00 & 0.00 & 0.00 & -0.001199 & -0.000612 & -0.009965 & -0.005275 \\
\hline
\end{tabular}




\section{c. Sistem Fuel Transfer Maximum}

Berdasarkan Tabel $\mathbf{3 . 1 2}$ dan 3.13, selisih moment saat di darat dan di udara sebelum transfer adalah 2001209,45 N.m dan sesudah transfer adalah 1399200,21 N.m. Sedangkan, tinggi defleksi saat di darat dan di udara sebelum transfer adalah $0,050972 \mathrm{~m}$ dan sesudah transfer adalah $0,044437 \mathrm{~m}$. Dengan diketahui selisih moment dan tinggi defleksi pada saat sebelum dan sesudah transfer pada kondisi di udara dan darat adalah 602009,24 N.m dan 0,006535 m.

\section{KESIMPULAN}

Berdasarkan hasil dan pembahasan yang terdapat pada bab sebelumnya, maka diperoleh kesimpulan sebagai berikut :

1. Hasil perhitungan distribusi berat sayap pada B 737-500, diawali dengan menentukan berat sayap keseluruhan sebesar 31343,661 N untuk kedua sayap pesawat, untuk satu sayap menjadi $15064,67 \mathrm{~N}$. Sayap pesawat dibagi menjadi 11 section. Dimana section 1 berada pada wing root dan section 11 berada pada wing tip. Berat terbesar pada section 3 dengan berat 21211,76 N, dikarenakan terdapat engine pada section tersebut.

2. Hasil perhitungan estimasi distribusi lift pada kondisi climb di ketinggian 10.000 ft yang telah dilakukan, didapatkan nilai total distribusi lift Pada sayap Boeing 737 - 500 dengan kondisi climb sebesar $257850,11 \mathrm{~N}$ di masing masing sayap, dimana lift maksimum terjadi di section 1 dengan nilai lift sebesar $37411,08 \mathrm{~N}$ dan nilai lift minimum terjadi di section 11 (wing tip) dengan nilai lift sebesar 0 $\mathrm{N}$.

3. Pada saat pentransferan constant, optimasi moment adalah 40134 N.m² dan tinggi defleksi 0,00164 m. Pada saat pentrasferan linier, optimasi moment adalah 48059,53 N.m ${ }^{2}$ dan tinggi defleksi 0,002004 m. Terakhir, pada saat pen-transferan maximum, optimasi moment adalah 177263,21 N.m ${ }^{2}$ dan tinggi defleksi $0,006535 \mathrm{~m}$. Dari data tersebut, di dapatkan optimasi terbaik pada saat pentrasferan maximum.

\section{DAFTAR PUSTAKA}

1. Vermeire, Frank., 2016, A380 Special Edition, FAST Magazine, Hal 44.

2. Utami, Fara Vania., 2018, Simulasi Optimasi Beban Bending pada Sayap dengan Sistem Fuel Transfer, Skripsi, Program Studi Teknik Penerbangan, Universitas Dirgantara Marsekal Suryadarma, Jakarta.

3. Boeing 777-300ER Wing Above Clouds, http://www.boeingimages.com/archive/ Boeing-777-300ER-Wing-AboveClouds-2F3XC5LC9X3.html, diakses 27 Juni 2018

4. Diverentia.,2016, Berbagai macam Jenis Pesawat terbang, http://sainsterbang.blogspot.com/2016/10/berbagaimacam-jenis-sayap-pesawat.html, diakses 14 april 2018.

5. Gere, J.M., 2009, Mekanika Bahan, Jilid 1, Edisi IV, Erlangga, Jakarta.

6. Al-Hussaini, A.A., 2013, Aircraft Design, Tesis, Mechanical Departemen, UOT, Canada.

7. Tulapurkara, Prof., 1998, Airplane Design (aerodinamic), Chapter 5, Dept Aerospace Eng, IIOT, Madras.

8. Brady, Chris., 1999, Detailed Technical Data,http://www.b737.org.uk/techspecs detailed.html, diakses 20 mei 2018

9. Torenbeek, E., 1982,Synthesis of Subsonic Airplane Design, Delt : Delft University Press.

10. Jenkinson, L., Simpkin, P., Rhodes, D., 1999, Civil Jet Aircraft Design, Penerbit Arnold : London.

11. Boeing Commercial Airplanes, 2013, Airplane Characteristic for Airport Planning, USA. http://www.boeing.com/ assets/pdf/commercial/airports/acaps/7 37.pdf, diakses 20 April 2018

12. Airbus, 2108, Aircraft Characteristics Airport and Maintenance Planning, France.http://www.airbus.com/content/d am/corporate-topics/publications/backg rounders/techdata/aircraft_characteristc s/Airbus-Commercial-Aircraft-AC-A320Feb18.pdf, diakses 16 April 2018.

13. 2016, Structure Repair Manual, Boeing, USA 